\title{
Comparison of Contamination of Bacteria Isolated from the External and Internal Surfaces of Cockroaches Collected from Several Hospitals in Hamadan City
}

\section{Farasat Habibi (MSc) ${ }^{1}$, Mansour Nazari (PhD) ${ }^{1, *}$, Babak Asghari (PhD) ${ }^{2}$, Seyed Mostafa Hosseini (PhD) ${ }^{2}$, Saman Nazari (MD) ${ }^{3}$, Sasan Nazari (MD) ${ }^{3}$}

${ }^{1}$ Department of Medical Entomology, School of Medicine, Hamadan University of Medical Sciences, Hamadan, Iran

2 Department of Microbiology, School of Medicine, Hamadan University of Medical Sciences, Hamadan, Iran

${ }^{3}$ Students Research Center, Hamadan University of Medical Sciences, Hamadan, Iran

* Corresponding Author: Mansour Nazari, Department of Medical Entomology, School of Medicine, Hamadan University of Medical Sciences, Hamadan, Iran. Email: ynazari@yahoo.com

Received: $14 / 12 / 2018$

Accepted: 13/02/2019

\section{How to Cite this Article:}

Habibi F, Nazari M, Asghari B, Hosseini SM, Nazari S, Nazari S. Comparison of Contamination of Bacteria Isolated from the External and Internal Surfaces of Cockroaches Collected from Some Hospitals in Hamadan City. Pajouhan Scientific Journal. 2019; 17(2): 54-60. DOI: $10.29252 / \mathrm{psj}$ 17.2.54

\section{Abstract}

Background and Objective: Cockroaches are one of the most important carriers of disease that involved human health, they can carry a great variety of pathogenic bacterial and then freely moved in the hospital environment. The presence of cockroaches in the hospital is a potential problem to the healthcare system. This study was aimed to determine the type of cockroaches and bacterial species in some hospitals of Hamadan University of Medical Sciences, Iran, 2017.

Materials and Methods: The present cross-sectional study was conducted in Fatemieh and Sina hospitals, Hamadan. 179 cockroaches were trapped at night and early morning from different parts of hospitals in a sterile condition. The insects were transported to the laboratory for analysis. To isolation and identification of bacteria, suspension prepared from the external surface and internal digestive tract of cockroaches. Bacteria species identification was performed by using selective media and specific diagnostic tests. Statistical analysis was done by using SPSS V.20.

Results: In this study, of the 179 cockroaches caught, 117 cockroaches were American (65.36\%) and 62 German cockroaches (34.64\%). Bacterial contamination was diagnosed in 173 (99.42\%) cockroaches. Our results revealed the maximum contamination was observed in American cockroach (648 (77.4\%) colony) and minimum contamination was observed the German cockroach (189 (22.6\%) colony). The most predominant species of bacteria isolated from American and German cockroaches were Escherichia coli 223(26.6\%), and the lowest found was Staphylococcus aureus 4(0.5\%).

Conclusion: Bacterial contamination of cockroaches in the hospital environment is an important concern in Hamadan health care systems. Moreover, antibiotic resistance observed in separated bacteria can enhance the pathogenicity of bacteria. So, we can conclude that cockroaches can contribute to the dissemination and spread of bacterial infection. Results suggest that elimination of cockroaches from human environments could reduce the bacterial infections.

Keywords: Bacterial Contamination; Cockroach; Hospital 


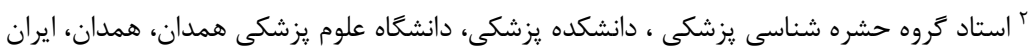

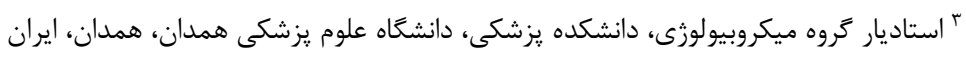

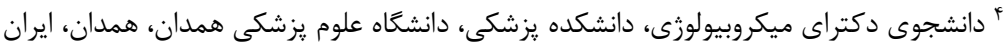

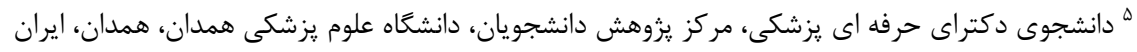
* نويسنده مسئول: منصور نظرى، گروه حشره شناسى يزشكى، دانشكده يزشكى، دانشگاه علوم يزشكى همدان، همدان، ايران. ايميل:ynazari@yahoo.com

\begin{tabular}{|c|c|}
\hline 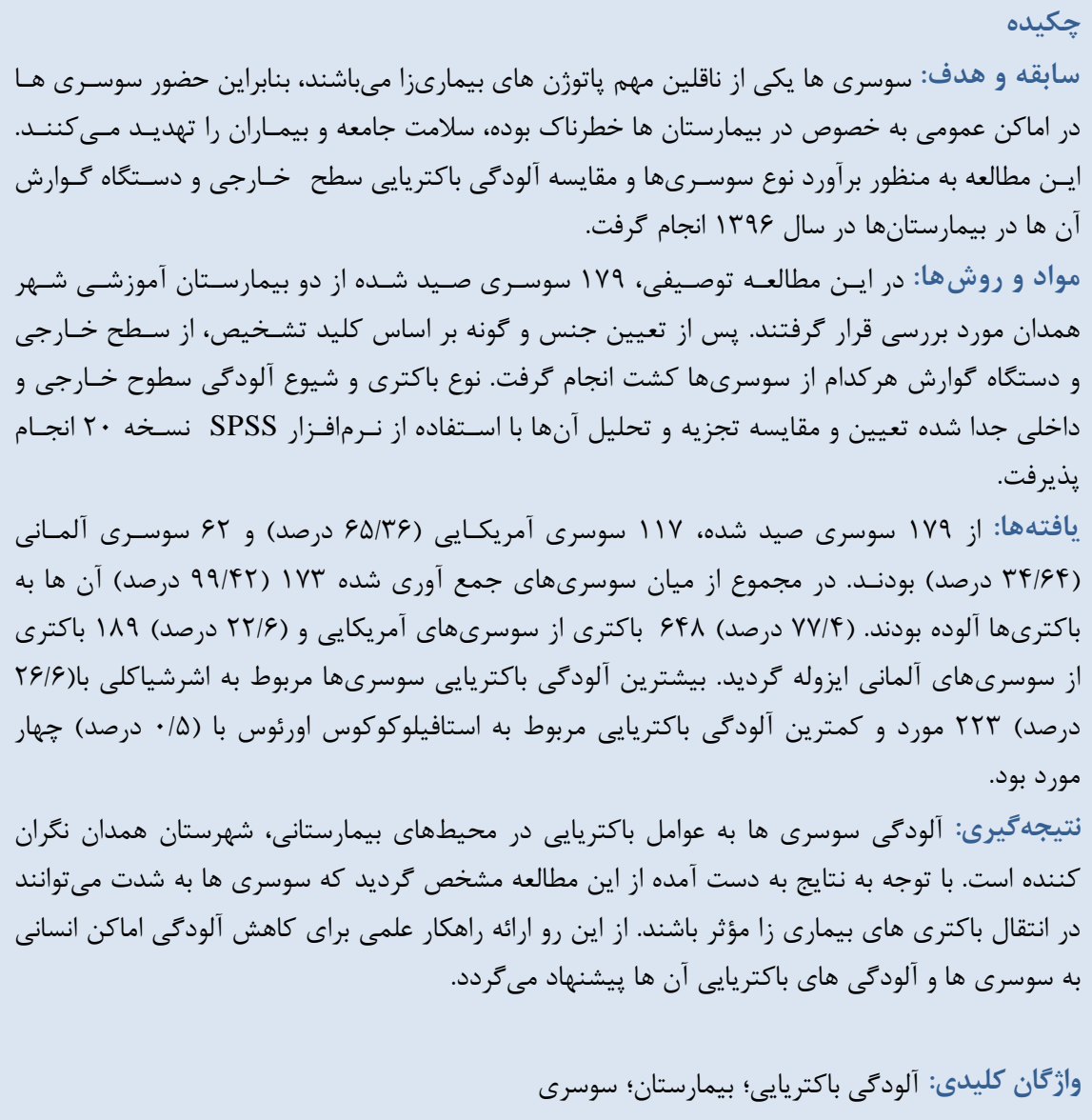 & 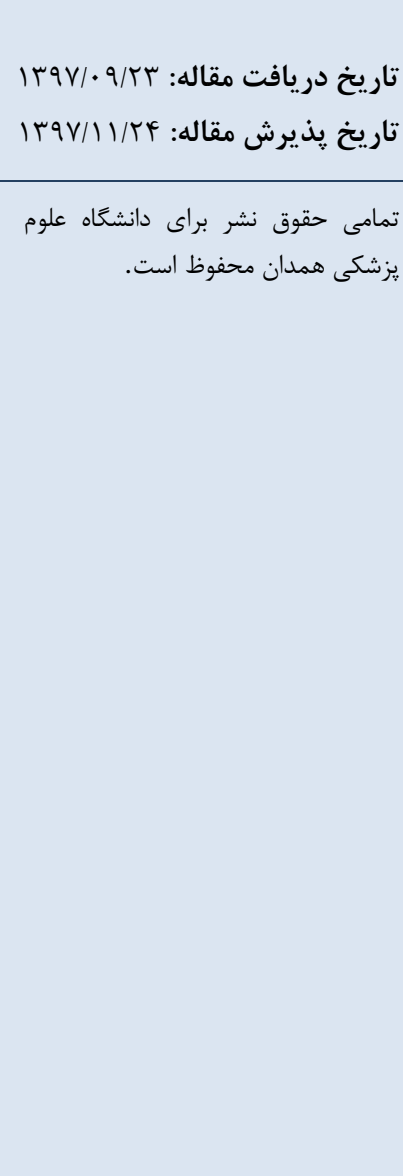 \\
\hline
\end{tabular}

كمتر از يك درصد از آنها جزء آفات محسوب مىشوند.

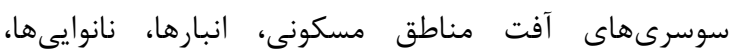

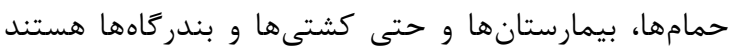

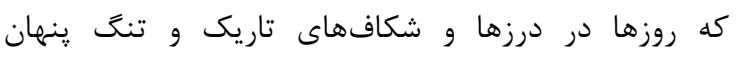

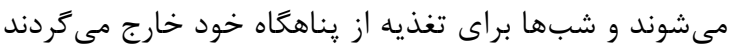

حشرات از پرجمعيت ترين ردههاى بنديايان هستند كه

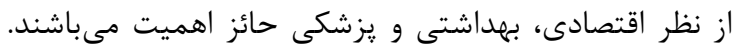

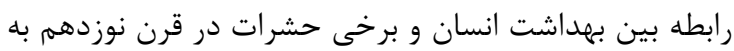

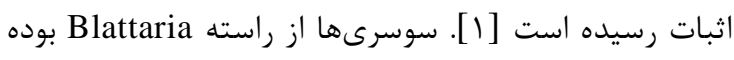

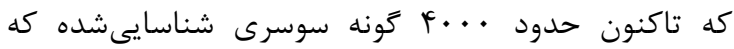




\section{مواد و روشها}

مكان هاى مورد مطالعه شامل دو بيمارستان آموزشى سينا

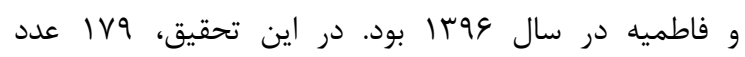

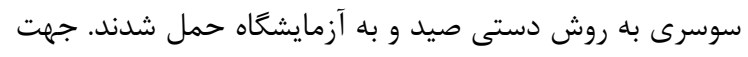

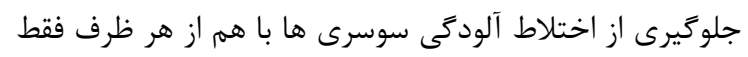

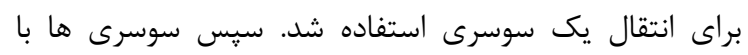

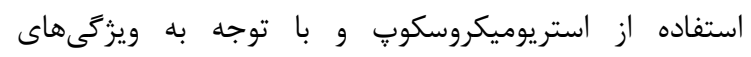
مورفولوزى از جمله خصوصيات اندازه، رنت و غيره تعيين هويت

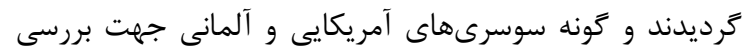
آلودگى باكتريايى مورد استفاده قرار كرفتند.

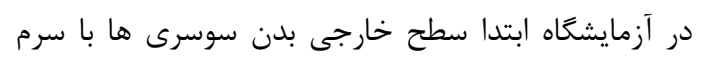

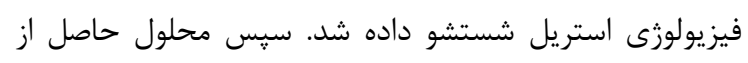
شستشوى سطح خارجى سوسرى ها در لوله هاى استريل جهت

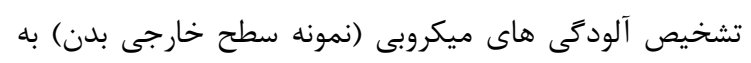

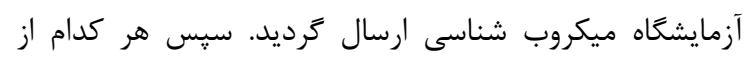

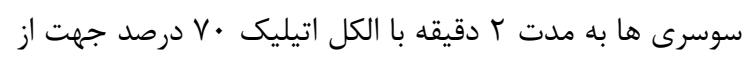

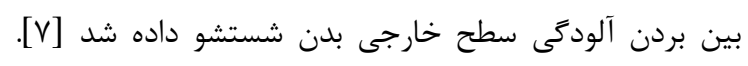

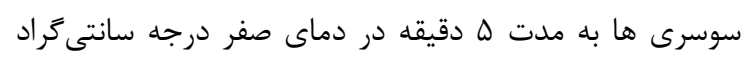

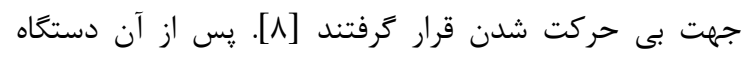

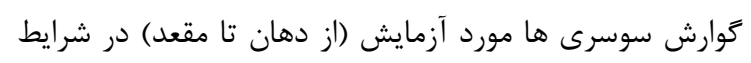

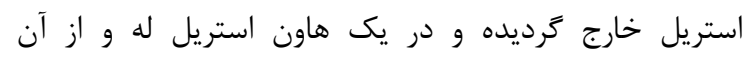
سوسيانسيون يكنواختى در ه سى سى سردي سرم فيزيولوزى استريل

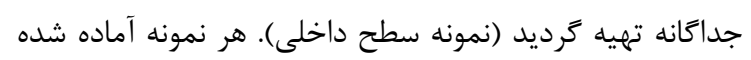

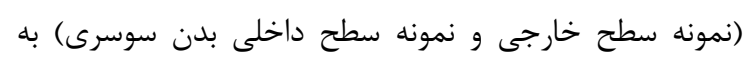

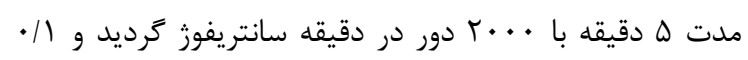

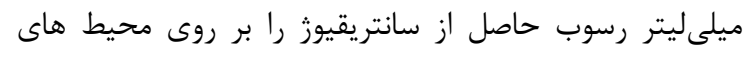

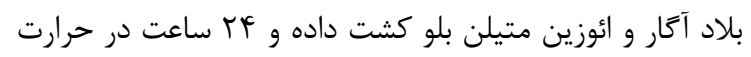

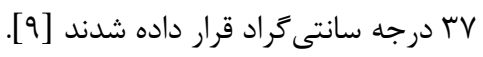

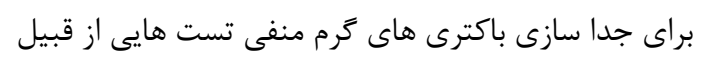

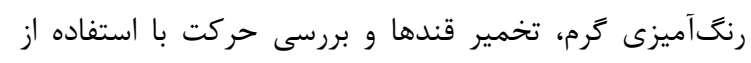

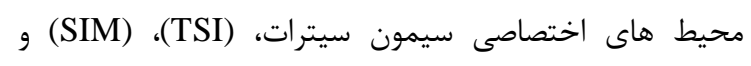

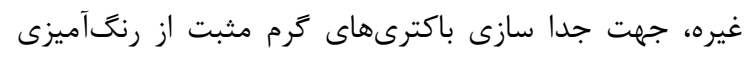

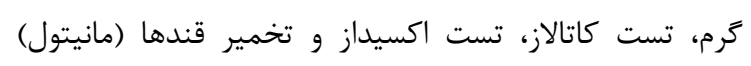

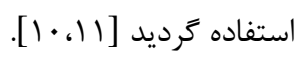

بافْته نا

در اين مطالعه از بيمارستان سينا ه9 عدد سوسرى كه

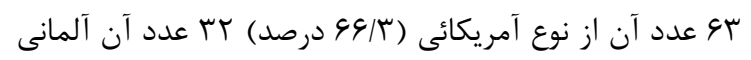

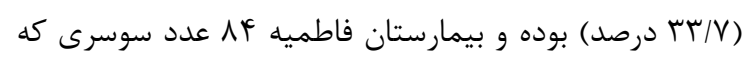

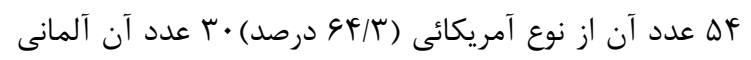

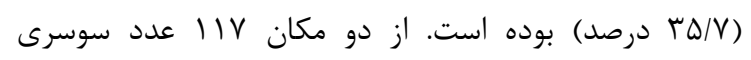

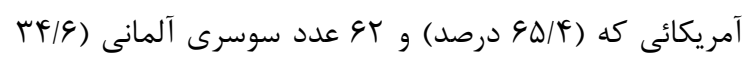

امروزه شايد كمتر مكانى را بتوان يافت كـهـ از حـضـور

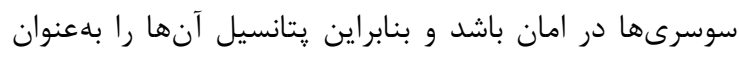

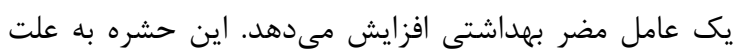

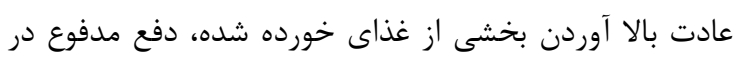

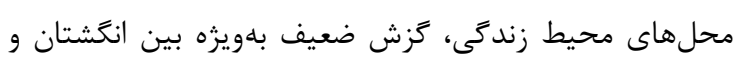

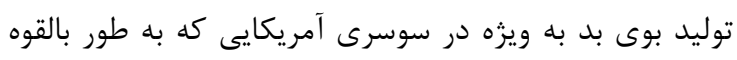

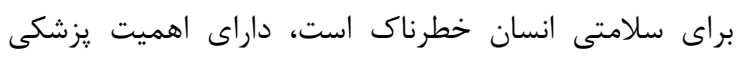

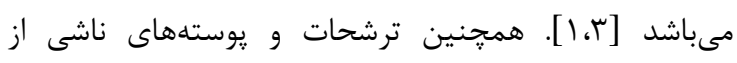

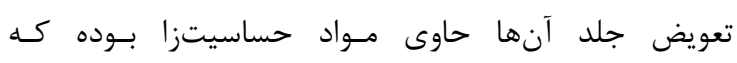

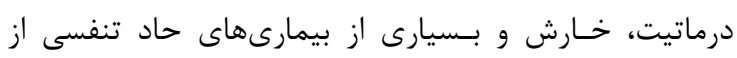
عوارض آنها است [F].

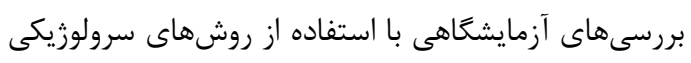

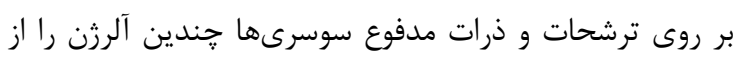

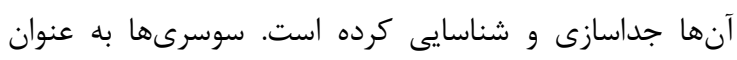

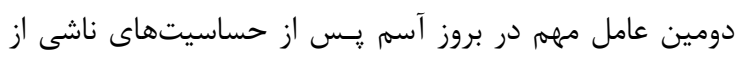

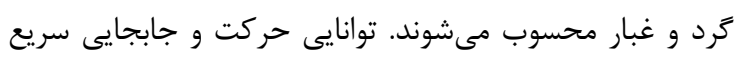

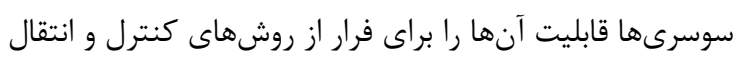

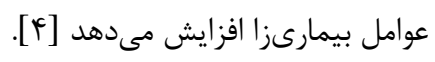

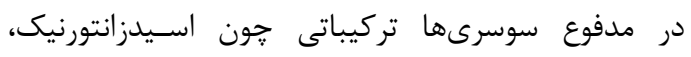
اسيدينورينك و اسيد ^ هيدروكسى كوينالديك وجود دارد كه

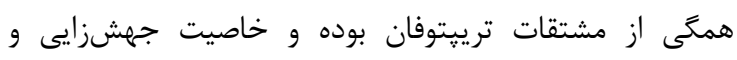

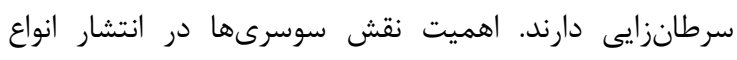

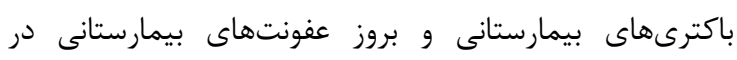

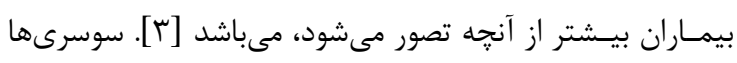

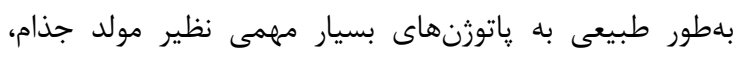

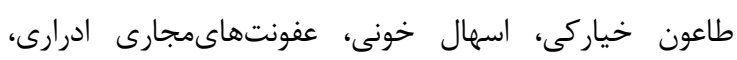

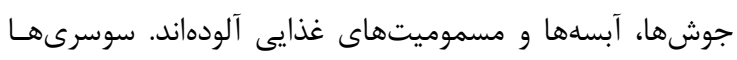

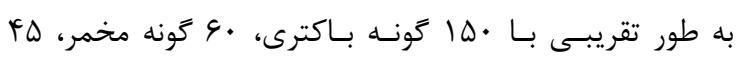

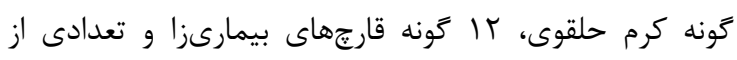

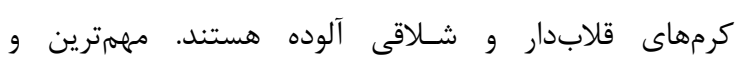
برجستهترين ناقلين باكترىهاى مذكور سوسرىهاى آداى آلمانى، آمريكايى و شرقى هستند [ه].

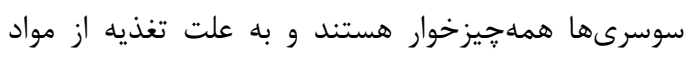

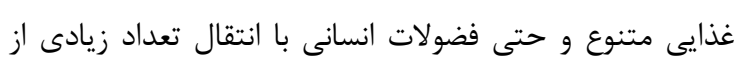

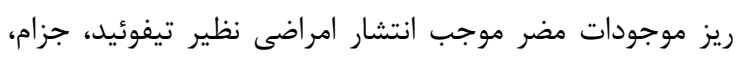

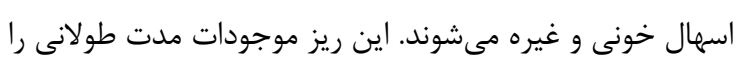

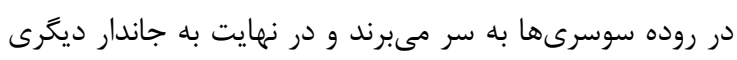
منتقل مى كردند [ع]. با توجه به فراوانى جمعيت سوسرى ها و نقش آنق آن ها در

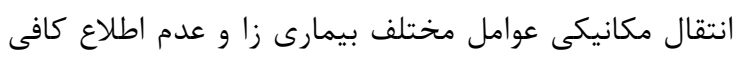

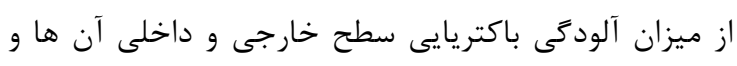

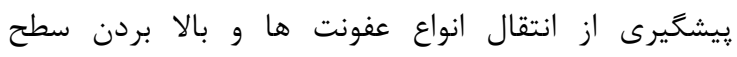
بهداشت عمومى تحقيق حاضر در محيط هاى بيمارستانى 
جدول r فراوانى باكترى ها را در هر يك از سوسرى ها برحسب گونه نشان مى دهد. بر اساس توزيع فراوانى باكترىهاى جدا سازى شده شده از

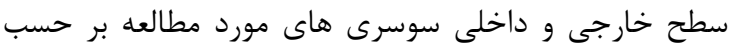

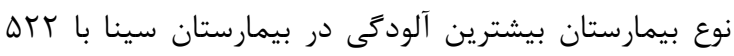

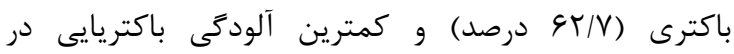

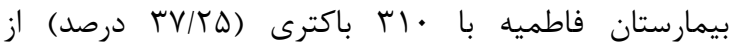

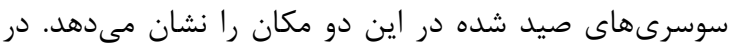

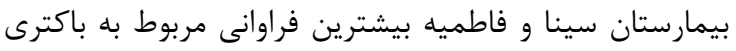

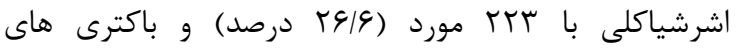

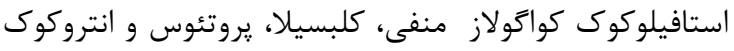

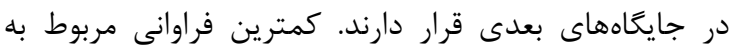

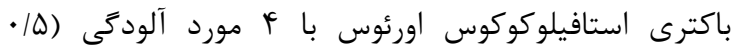

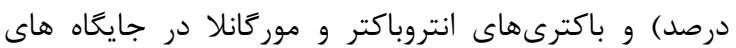
بعدى قرار دارند. بر اساس مقدار P به دست آمده مىتوان

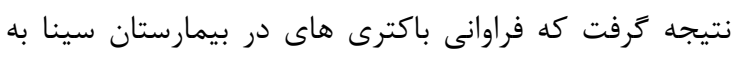

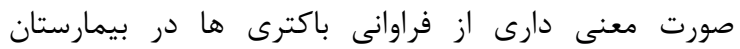

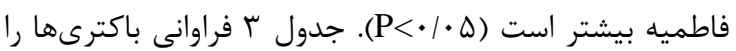
در سوسرى ها بر حسب بيمارستان نشان مىدهد.
IV9 بوده صيد زرديد. در مجموع از اين دو مكان سوسرى صيد شده است. جدول ا فراوانى سوسرىها را بر مرديد

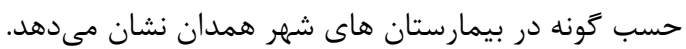

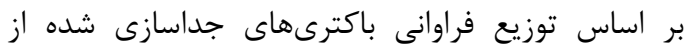

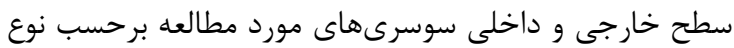

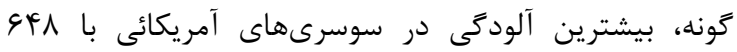

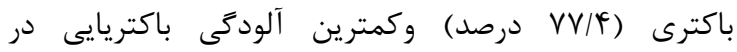

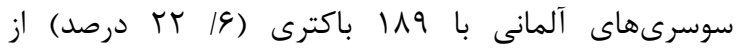

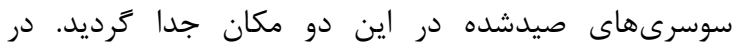

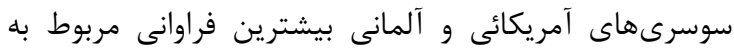

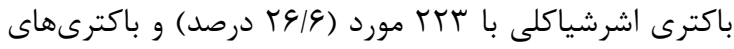

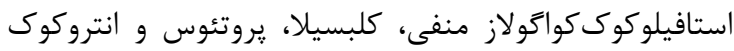

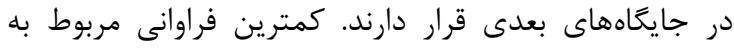

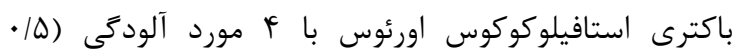

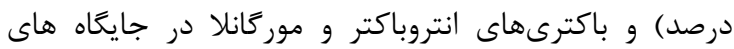

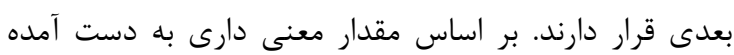

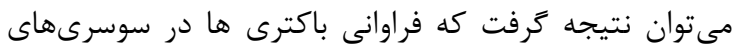

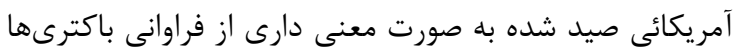

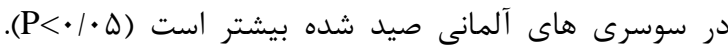

جدول ا: فراوانى مطلق و نسبى سوسرىها در بيمارستان هاى شهر همدان

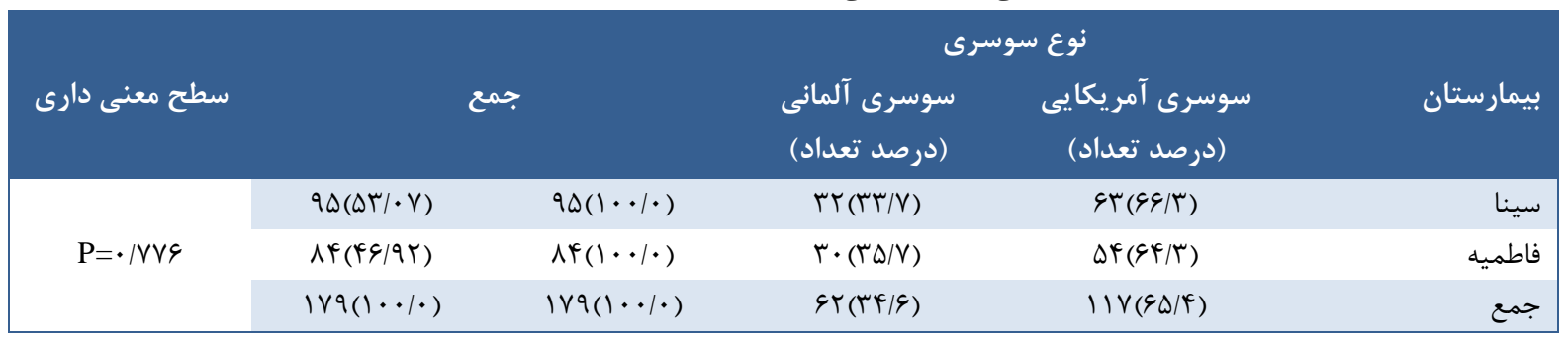

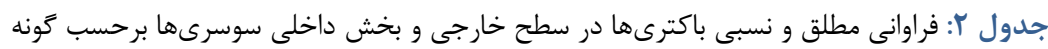

\begin{tabular}{|c|c|c|c|c|}
\hline سطح معنى دارى & مجموع & سوسرى آلمانى (درصد) تعداد & سوسرى آمريكائى (درصد) تعداد & 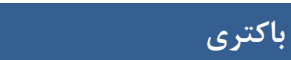 \\
\hline \multirow{15}{*}{$\mathrm{P}<\cdot / \cdot \cdot 1$} & TrT (T\&|\&) & $r r(I T / T)$ & $r \cdot(r \cdot / 9)$ & اشرشياكلى \\
\hline & $\operatorname{IAV}(Y T / T)$ & rT (IT/T) & $1 \& Y(T \Delta / T)$ & استافيلوكوك كواتولاز منفى \\
\hline & $|\wedge|(Y \mid / 9)$ & $r \Delta(\mid N / \Delta)$ & IF\& (YY/Q) & كلبسيلا \\
\hline & $\Delta V(\varepsilon / \Lambda)$ & $\|(\Delta / \Lambda)$ & is $(V / I)$ & يروتئوس \\
\hline & FI $(F / q)$ & $\Leftrightarrow(r / T)$ & $r \Delta(\Delta / \mathcal{\epsilon})$ & انتروكوك \\
\hline & $r \Delta(\boldsymbol{F} / T)$ & $11(9 / 0)$ & IV $(T / 9)$ & 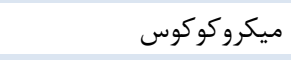 \\
\hline & $r \cdot(T / \mathcal{Y})$ & $r \cdot(1 \cdot 19)$ & $\cdot(\cdot / \cdot \cdot)$ & سراشيا \\
\hline & $19(T / \pi)$ & $r(1 / 1)$ & IV (Y/9) & سودوموناس \\
\hline & $19(T / T)$ & $r(1 / 9)$ & $19(\Gamma / \Delta)$ & استريتوكوى B \\
\hline & $\operatorname{lr}(1 / \mathcal{F})$ & Ir $(\varphi / r)$ & $\cdot(\cdot / \cdot \cdot)$ & استريتوكوى A \\
\hline & $\wedge(1)$ & $1(/ \Delta)$ & $V(1 / 1)$ & مورگًانلا \\
\hline & $\wedge(1)$ & $\Lambda(\mathcal{F} / \Gamma)$ & $\cdot(\cdot / \cdot \cdot)$ & انتروباكتر \\
\hline & $f(\cdot \mid \Delta)$ & $F(T / I)$ & $\cdot(\cdot / \cdot \cdot)$ & استافيلوكوكوس اورئوس \\
\hline & $r \quad(T / V)$ & $r(T / T)$ & $\cdot(\cdot / \cdot \cdot)$ & باكترى مشاهده نغرديد \\
\hline & Arv $(1 \cdot \cdot / \cdot)$ & $119(Y T / 9)$ & GFA $(V V / F)$ & مجموع \\
\hline
\end{tabular}




\begin{tabular}{|c|c|c|c|c|}
\hline سطح معنى دارى & 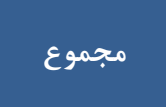 & بيمارستان فاطميه & تعداد (درصدار & باكترى \\
\hline \multirow{15}{*}{$\mathrm{P}<\bullet / \cdot \cdot 1$} & TTH (TG/9) & $99(\Gamma \cdot 10)$ & $I T V(T Y / T)$ & اشر شياكلى \\
\hline & IAV (TY/T) & $\Delta \Delta(I V / \Delta)$ & ITr $(T \Delta / T)$ & استافيلوكوك كواكولاز منفى \\
\hline & $|\wedge|(Y \mid / 9)$ & $\Delta \cdot(1 \Delta / 9)$ & $|r|(r \Delta / I)$ & كلبسيلا \\
\hline & $\Delta V(\varepsilon / \Lambda)$ & TT (V) & $r_{\omega}(g / V)$ & يروتئوس \\
\hline & fi $(f / q)$ & 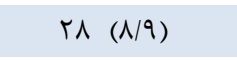 & $\mathbb{I r}(Y / D)$ & انتروكوى \\
\hline & $r \Delta(\mathcal{F} / T)$ & $r(V / T)$ & $\mathbb{I r}(T / T)$ & ميكروكوكوس \\
\hline & $r \cdot(Y / F)$ & $\cdot(\cdot / \cdot \cdot)$ & $r \cdot(r / \Lambda)$ & سراشيا \\
\hline & $19(T / T)$ & $\cdot(\cdot / \cdot \cdot)$ & $19(1 / 9)$ & استر يتوكوى B \\
\hline & $19(T / T)$ & IV $\left(\Delta / \mathcal{F}^{\mathcal{L}}\right)$ & $r\left(\cdot / F^{\mathbb{E}}\right)$ & سودوموناس \\
\hline & IT $(1 / \mathbb{F})$ & $\cdot(\cdot / \cdot \cdot)$ & $\mathbb{I r}(r / r)$ & A استريتوكوى A \\
\hline & $\wedge(1)$ & $\cdot(\cdot / \cdot \cdot)$ & $\wedge(1 / \Delta)$ & موركانلا \\
\hline & $\wedge(1)$ & $\cdot(\cdot / \cdot \cdot)$ & $\wedge(1 / \Delta)$ & انتروباكتر \\
\hline & $f(\cdot \mid \Delta)$ & $f(1 / r)$ & $\cdot(\cdot / \cdot \cdot)$ & استافيلوكوكوس اورئوس \\
\hline & $r \Psi(T / V)$ & $r \cdot(r / \mathcal{Y})$ & $r(\cdot \mid q)$ & باكترى مشاهده نَرديد \\
\hline & $\Lambda r \gamma(1 \cdot \cdot / \cdot)$ & TID (TV/q) & $\operatorname{DrT}(G T / \mathcal{F})$ & مجموع \\
\hline
\end{tabular}

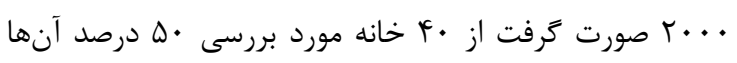
آلوده بوده و درصد آلودگى به سوسرى آمريكائى با لا لا منزل

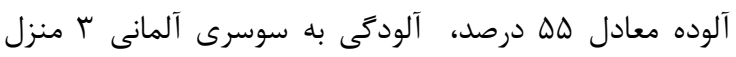

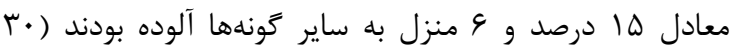

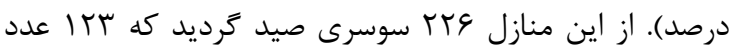

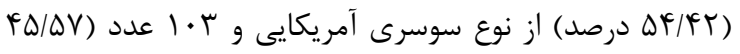

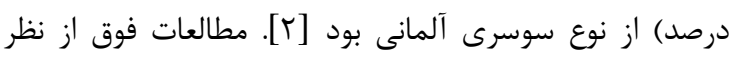

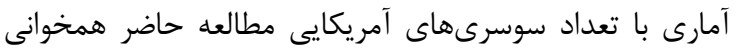

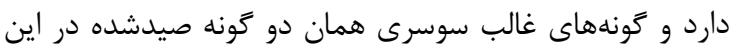

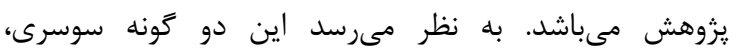

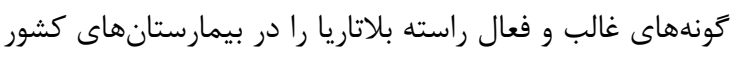

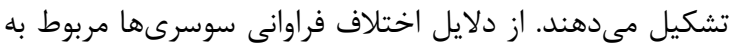

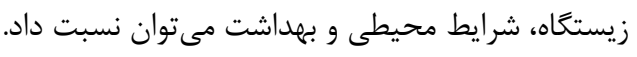

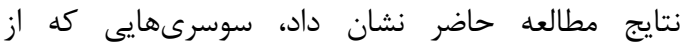

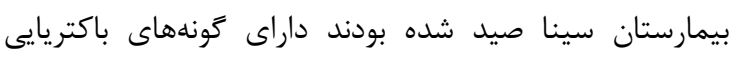

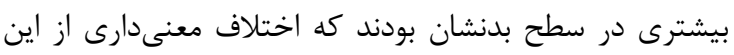

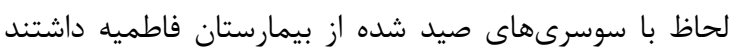

$$
(P<\cdot / \cdot \Delta)
$$

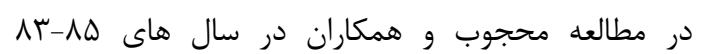

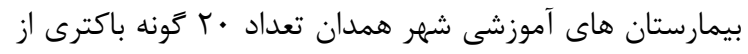

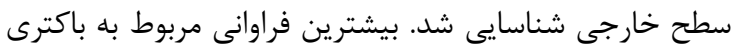

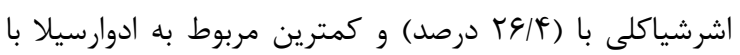

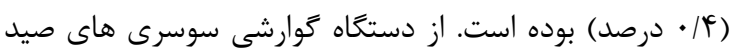

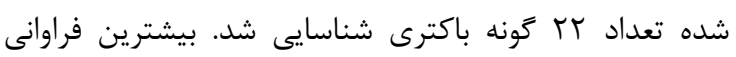

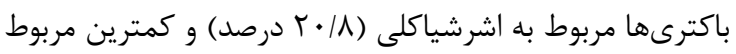

بيمارستان هميشه مكانى نيست كه بيماران در آن بهبود

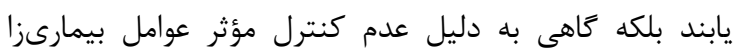

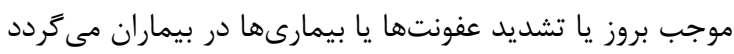

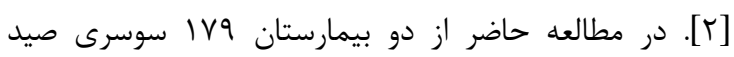

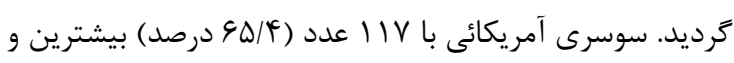

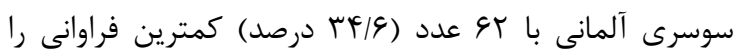
داشته تحقيق فوق نشان داد كه دو گَونه سوسرى آمريكائى و

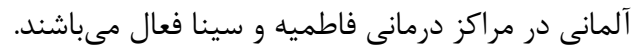

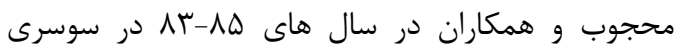

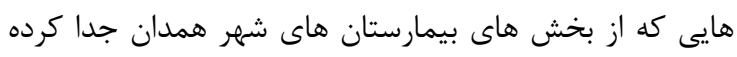

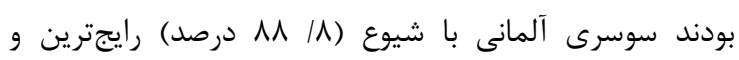

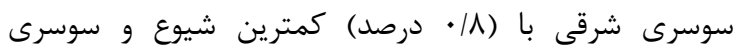

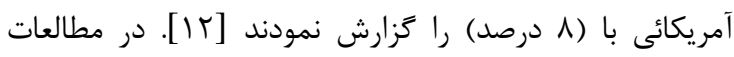

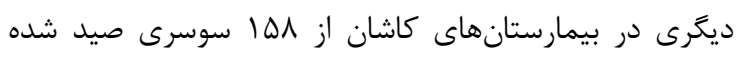

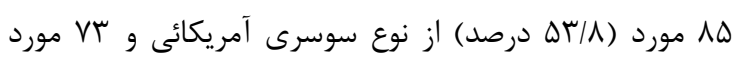

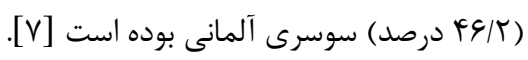

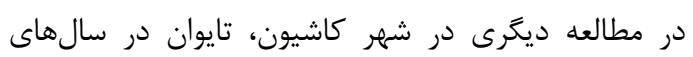

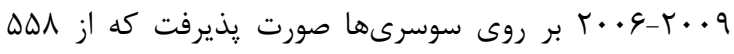

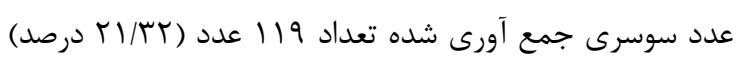

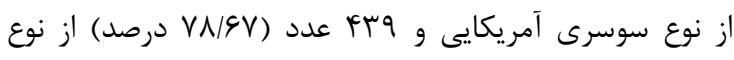

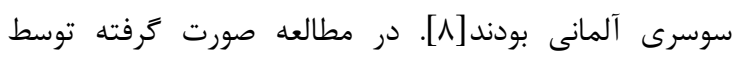

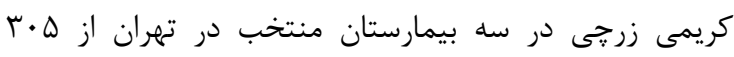

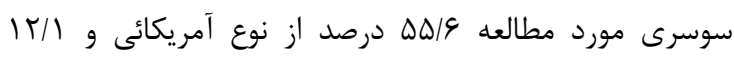

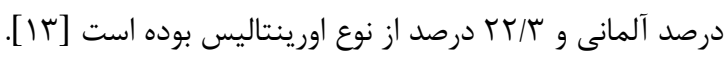
در مطالعه ديخرى كه در شهر كاشيون در تايوان سال 
اختلاف در نوع باكترىهاى موجود در بيماران و كاركنان اين دو مركز باشد.

باكترى اشرشياكلى رايجترين باكترى بيمارىزا است كه در

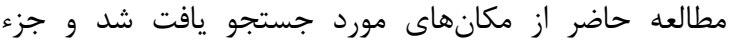

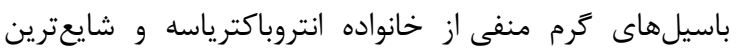

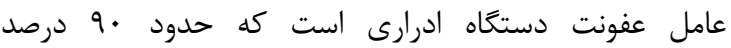
عفونتهاى ادرارى در زنان جوان را به خود اختصاص مى دهديد. علائم بالينى اين عفونت به صورت تكرر ادرى ادرار، سوزش، ادروان ادرار خونى و ادرار جركى است [IV]

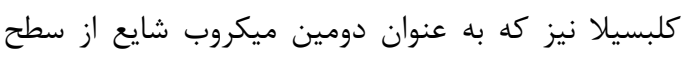

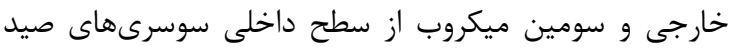

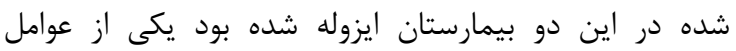
عفونتزا بخصوص عفونتهاى ادرارى و تنفسى در درو بيماران بسترى در بيمارستانها به شمار مىرود [11]

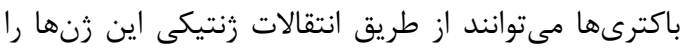

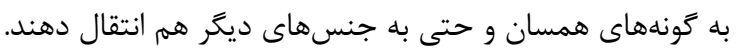
در هر حال بعيد نيست كه نقش سوسرىها درى در ايجاد عفونتهاى بيمارستانى بسيار مهمتر از جيزى باشد كه به نظر نهر نهر

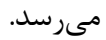

\section{نتيجه تيرى}

با توجه به نتايج به دست آمده از اين مطالعه مشخص

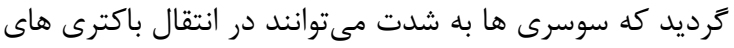

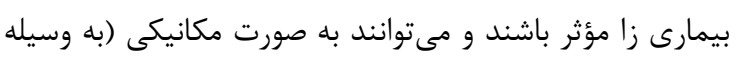

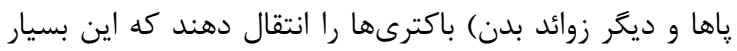

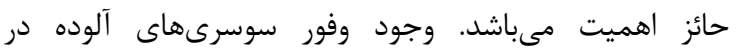
محيطهاى حساس بيمارستان بسيار خطرناك بوده و سلامت

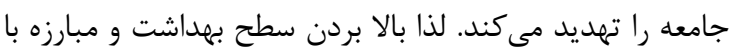

$$
\text { سوسرىها بسيار ضرورى به نظر مىرسد. }
$$

\section{تشكر و قروراذى}

اين مطالعه حاصل پايان نامه دانشجوى كارشناس ارشد

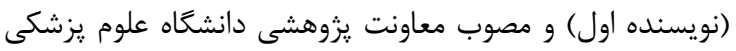

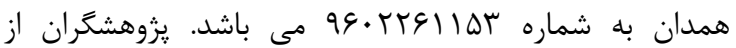

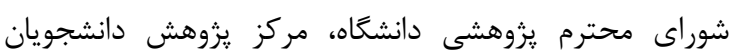

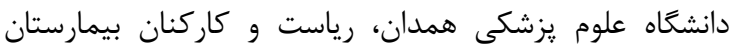

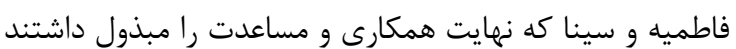
تشكر و امتنان را دارند.

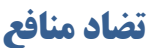
اين مطالعه براى نويسندكان هيج گَونه تضاد منافعى نداشته

\section{REFERENCES}

1. Zaeim M Seyedi Rashti M SM. Aguide to medical
به انتروباكترآكومرانس، سالمونلاياراتيفى آ (//T درصد) بوده

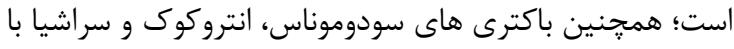
شيوع بالا از بدن سوسرى هاى بيمارستانى جدا كرديد. سالمونلا

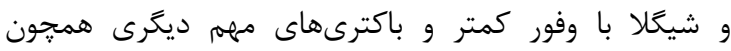

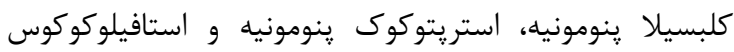
اورئوس جدا كرديده مىتواند دليلى كافى بر بيان ميزان آلودكى آلى

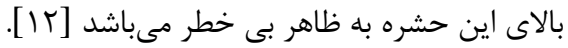

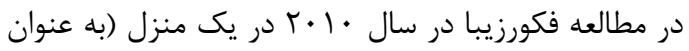
كنترل) و سه بيمارستان در شهر تهران انجام كرديد، بيشترين فراوانى را گونه هاى جنس كلبسيلا و در مرحله بعد انتروباكتر

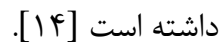

در مطالعهاى كه توسط كريمى زرجى در سله سله بيمارستان

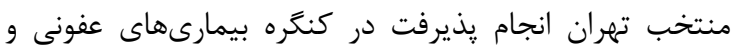

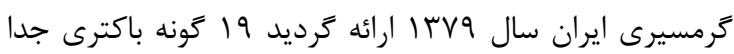
كرديد كه در بين آنها اشيرشياكلى بيشترين درصد آنس آلودى آنى

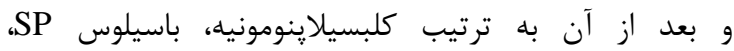

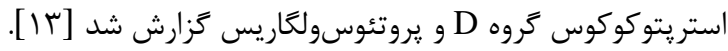
در تحقيقى كه توسط lin در كشور جين شهرو هاينان انجام

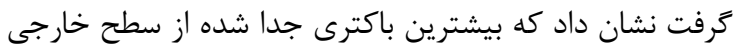

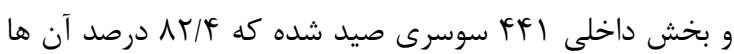

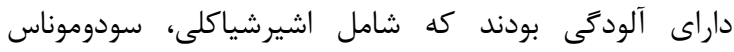

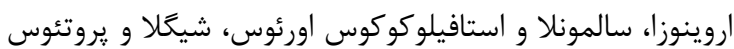

بوده است [1ه].

در تحقيق ديغرى كه توسط Chaichanawongsaroj در

بانكوى تايلند بر روى 99 سوسرى صيد شده از محيط هاى دوسئ

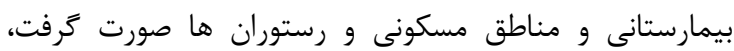

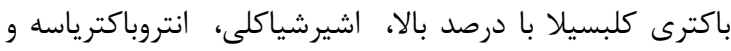

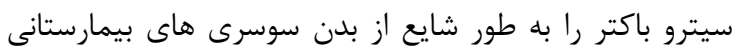

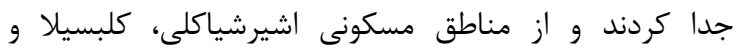

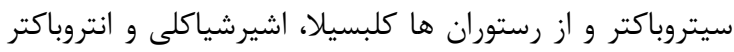

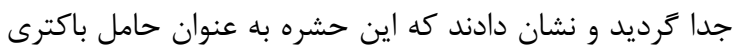

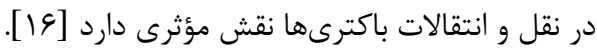

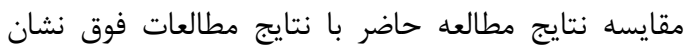

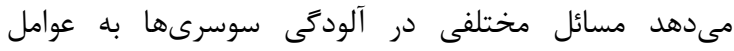

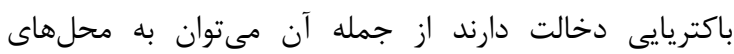

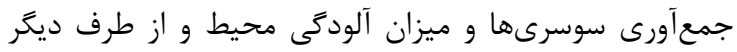

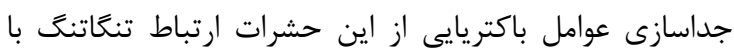

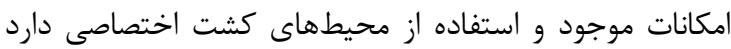

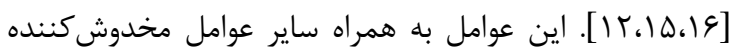

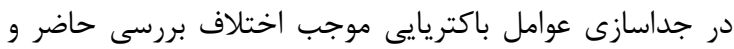
مطالعات مشابه در باكترىهاى ايزوله شده مىشودي موردي

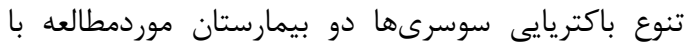

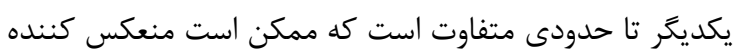

entomology. Sciences TTuoM, editor 2008: 325-30.

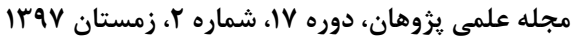


2. Pai H-H, Chen W-C, Peng C-F. Cockroaches as potential vectors of nosocomial infections. Infection Control \& Hospital Epidemiology. 2004; 25(11):979-84

3. McGowan EC, Peng R, Salo PM, Zeldin DC, Keet CA. Cockroach, Dust Mite, and Shrimp Sensitization orrelations in The National Health and Nutrition Examination Survey. Ann Allergy Asthma Immunol. 2019: S1081-1206 (19)30128-0. DOI: 10.1016/j.anai.2019.02.015. [Epub ahead of print].

4. Cloarec A, Rivault C, Fontaine F, Le Guyader A. Cockroaches as carriers of bacteria in multi-family dwellings. Epidemiology \& Infection. 1992;109(3):483-90.

5. Levin ML. Medical entomology for students. Emerging infectious diseases. 2014;20(8):1428.

6. Arruda LK FV, Vailes LD, Pomes A,Chapman MD. Cockroach allergns:environmental distribution and relationship to disease. Current allergy and asthma reports. 2001:1(5):466-73.

7. Doroodgar A, Khorshidi A, Shajari GR, Tashakkor Z. Bacterial infection of cockroaches in Kashan hospitals, 2001. KAUMS Journal (FEYZ). 2005;8(4):30-8.

8. Pai $\mathrm{H}-\mathrm{H}$. Multidrug resistant bacteria isolated from cockroaches in long-term care facilities and nursing homes. Acta tropica. 2013;125(1):18-22. DOI: 10.1016/j. actatropica.2012.08.016.

9. Salehzadeh A, Tavacol P, Mahjub H. Bacterial, fungal and parasitic contamination of cockroaches in public hospitals of Hamadan, Iran. Journal of vector borne diseases. 2007;44(2):105.

10. Nazari M, Mehrabi T, Hosseini SM, Alikhani MY. Bacterial Contamination of Adult House Flies (Musca domestica) and Sensitivity of these Bacteria to Various Antibiotics, Captured from Hamadan City, Iran. Journal of clinical and diagnostic research: JCDR. 2017;11(4):DC04. DOI: 10.7860/JCDR/2017/23939.9720.
11. Hosseini SM, Zeyni B, Rastyani S, Jafari R, Shamloo F, Tabar Z, et al. Presence of virulence factors and antibiotic resistances in Enterococcus sp collected from dairy products and meat. Der Pharmacia Lettre. 2016;8(4):138-45.

12. Mahjoob M, Nejate G, Keihane A. Bacterial contamination of external surface and gut of cockroaches in teaching hospital, Hamadan. Hormozgan Med J. 2010;14(1):80-6.

13. Zarchi AAK, Vatani H. A survey on species and prevalence rate of bacterial agents isolated from cockroaches in three hospitals. Vector-Borne and Zoonotic Diseases. 2009; 9(2):197-200.

14. Fakoorziba M, Eghbal F, Hassanzadeh J, MoemenbellahFard M. Cockroaches (Periplaneta americana and Blattella germanica) as potential vectors of the pathogenic bacteria found in nosocomial infections. Annals of Tropical Medicine \& Parasitology. 2010;104(6):521-8

15. Lin Y, Cui Y, Yang W, Rao L, Pan W, Chen J. Investigation on species composition of cockroaches and bacteria-carrying on their bodies in five cities of Hainan. Zhongguo ji sheng chong xue yu ji sheng chong bing za zhi= Chinese journal of parasitology \& parasitic diseases. 2008;26(1):77-8.

16. Chaichanawongsaroj N, Vanichayatanarak K, Pipatkullachat T, Polrojpanya M, Somkiatcharoen S. Isolation of gramnegative bacteria from cockroaches trapped from urban environment. Southeast Asian J Trop Med Public Health. 2004;35(3):681-4

17. Kaper JB, Nataro JP, Mobley HL. Pathogenic escherichia coli. Nature Reviews Microbiology. 2004; 2(2):123-40. DOI: 10.1038/nrmicro818.

18. Najjuka CF, Kateete DP, Kajumbula HM, Joloba ML, Essack SY. Antimicrobial susceptibility profiles of Escherichia coli and Klebsiella pneumoniae isolated from outpatients in urban and rural districts of Uganda. BMC Res Notes. 2016;9:235. DOI:10.1186/s13104-016-2049-8. 